\title{
INVERSÃO NO BALANÇO MIGRATÓRIO MINEIRO: AS TROCAS POPULACIONAIS ENTRE MINAS E SÃO PAULO
}

\author{
Ralfo Matos* \\ Carlos Lobo \\ João Stefani
}

\section{Resumo}

Minas Gerais tem perdido população para o estado de São Paulo há pelo menos 100anos. Os fluxos migratórios entre tais Unidades da Federação expressavam trocas populacionais muito desiguais, amplamente favoráveis a São Paulo, sobretudo no período 1940-1980. Sucessivos momentos de dificuldades econômicas que Minas enfrentou certamente explicam seu perfil emigratório tão persistente. Entretanto, mudanças nas trocas entre São Paulo e Minas já podiam ser observadas nos dados do Censo de 1991, quando mostrava o declínio do nível de perdas do estado em relação aSão Paulo. Os dados do Censo de 2000 não só confirmam essa tendência como indicam um quadro novo. Pela primeira vez, Minas Gerais exibe saldo migratório positivo em suas trocas com São Paulo. A expansão da área de influência de São Paulo no Sudeste pode estar criando novas territorialidades, que vêm absorvendo parte dos efeitos do processo de desconcentração econômica e demográfica da metrópole paulista. Minas Gerais certamente participa desse processo. Assim sendo, os dados devem, em alguma medida, expressar essa evidência. Regiões como as do Sul de Minas, Triângulo e Mata, a princípio, seriam as áreas ganhadoras por excelência, em face da proximidade com o estado de São Paulo. Os dados mostram, no entanto, que outras regiões de Minas também tiveram alteradas suas relações de trocas com São Paulo. O trabalho analisa parte dessas novas evidências empíricas, procurando identificar e comparar os aspectos referentes ao perfil socioeconômico dos migrantes, tendo em conta a distribuição dos fluxos migratórios inter-regionais e intermunicipais,além da contribuição da migração de retorno a UF.

\footnotetext{
* Professor do Departamento de Geografia do IGC/UFMG, doutor em Demografia.

- Professor do Centro Universitário de Belo Horizonte (UNI-BH), mestre em Geografia.

- Professor do Centro Universitário de Belo Horizonte (UNI-BH), mestre em Geografia.
} 


\section{1- INTRODUÇÃO*}

Por mais de 100 anos, Minas Gerais foi um dos maiores perdedores de população do Brasil. O dinamismo dos principais centros do sudeste, ou nas fronteira agrícolas em expansão, associado às recorrentes dificuldades econômicas internas, pode ser visto como importante fator na evolução da emigração mineira ao longo do século XX.Talvez, para além das desigualdades territoriais existentes, a condição emigratória de Minas Gerais não tivesse se revelado com tanta intensidade sem a grande acumulação depopulação que o estado experimentou por muito tempo, especialmente ao longo do século XIX. Ainda no início do século XX, Minas abrigava perto de 1/5 da população brasileira e seu crescimento vegetativo era relativamente alto. O fator demográfico, portanto, auxilia na explicação dos impressionantes saldos migratórios negativos que Minas Gerais acumulou em grande parte do século XX. Com tão expressivos estoques populacionais e diante da perda do dinamismo da economia mineira em fins do século XIX não seria surpresa a liberação decrescentes contingentes populacionais.

Com as primeiras décadas do século XX e a intensificação do processo de industrialização e urbanização concentrado, aumentaram as saídas de migrantes rumo ao estado São Paulo, e um pouco depois, rumo às fronteiras agrícolas no norte do Paraná e do Centro-Oeste (Coelho, et. al., 1982). Se de um lado a pujança econômica paulista operava como um fator de atração populacional, de outro a decadência de determinadas regiões mineiras mostrava-se patente, sobretudo nas áreas rurais ${ }^{1}$.

Em meados do século passado o estado de São Paulo, e principalmente sua região metropolitana, consolida a posição de principal área receptora de emigrantes de Minas Gerais.Na década de 1970, ponto culminante dos grandes saldos migratórios brasileiros como mostra RIGOTTI (1999), São Paulo apresenta o maior saldo migratório intercensitário da história brasileira, exibindo um ganho de mais de 3,5 milhões de pessoas (somado o efeito indireto).Nesse decênio, Minas Gerais já apresentava um arrefecimento de suas perdas populacionais,que se refletia na redução do saldo negativo (de mais de 1,4 milhão de pessoas, contra 1,6milhão na década anterior). Essa tendência de redução se confirmou com os dados referentes à década de 1980, quando o saldo migratório negativo atingiu valores próximos a 800 mil pessoas. Nesse momento, a economia brasileira passava por uma situação de crise, com escassez de postos no mercado de

\footnotetext{
${ }^{*}$ Esse artigo integra-se a uma pesquisa maior financiada pelo CNPq.

${ }^{1}$ Cabe observar que, apesar das sucessivas perdas de população nas décadas de 1950 e 1960 , regiões como a Zona Metalúrgica, e principalmente a atual Região Metropolitana de Belo Horizonte, destacavam-se como importantes áreas receptoras de população, apresentando altas taxas de crescimento demográfico. Na década de 1960, a regiãometropolitana que mais crescia no Brasil era a de Belo Horizonte, embora no decênio seguinte, já se podia perceber o decréscimo de suas taxas líquidas de migração (RIGOTTI, 1999).
} 
trabalho dos grandes centros urbano. Do ponto de vista demográfico, a mortalidade e a fecundidade experimentavam sucessivos declínios. Com isso,os grandes volumes de população excedente tendiam a diminuir, em meio a mudanças na própria dinâmica migratória (MATOS, 1995).

Dados demográficos mais recentes permitem identificar novos padrões nas trocaspopulacionais envolvendo o estado de São Paulo. O Censo de 1991 mostrava arrefecimentoem seu ritmo de crescimento e, pela primeira vez, a região metropolitana de São Paulo comsaldo migratório negativo de 274.000 pessoas. A capital paulista teria sido a principalresponsável pela perda líquida de população na década de 1980, com saldo negativo de750.000 pessoas (BAENINGER, 1997). Essa alteração no balanço migratório paulista foiresultado direto da queda na imigração e do aumento da emigração, particularmente sob aforma de emigrantes que retornavam aos seus estados de origem. Na década seguinte, osdados de migração de data fixa, referentes ao período de 1995-2000, confirmam as tendênciasanteriores, mostrando um fato inédito: a inversão da posição de Minas em relação a São Paulono que diz respeito às trocas de população. Os migrantes procedentes de São Paulo eramsuperiores aos que os saíram de Minas.

No interior dessa mudança, é provável que novas territorialidades estejam seafirmando em Minas Gerais, o que explicaria parte da reversão nos padrões de trocas, já quemudanças econômicas em curso podem ampliar o grau de proximidade e interação entreregiões que, histórica e geograficamente, sempre estiveram interligadas a São Paulo, aexemplo do Sul de Minas e Triângulo Mineiro, ou mesmo Campo das Vertentes, Oeste deMinas e Noroeste. De outro lado, as trocas entre as regiões menos próximas, como a própriaRegião Metropolitana de Belo Horizonte, também podem sugerir facetas menos óbvias doprocesso migratório, de acordo com o tipo de migrante em questão. Nesse sentido, algumasregiões mineiras permanecem perdendo população para o estado de São Paulo, tais como oarco nordeste/norte (Doce, Mucuri, Jequitinhonha e Norte), mesmo que ainda recebam umnúmero não desprezível de migrantes de retorno.

\section{2 - INVERSÃO MIGRATÓRIA: GANHOS E PERDAS NAS TROCAS ENTRE MINAS E SÃO PAULO}

De 1991 a 2000, Minas Gerais apresentou uma taxa de crescimento demográfico de 1,4\% ao ano, valor inferior ao verificado no país (aproximadamente 1,6\% a.a.). Aos15.743.533 de residentes em 1991, somaram-se 2.161.601 pessoas nesse período.Regionalmente, destacou-se a mesorregião Metropolitana de Belo Horizonte, que, mediante seu crescimento de 2,1\% a.a., 
ampliou seu peso relativo em Minas, dos 29,3\% em 1991,passou a concentrar 31,2\% da população mineira no ano 2000 (Tabela 1). Com menor expressão, também merecem ser citadas as mesorregiões do Triângulo Mineiro/Alto Paranaíba, Oeste de Minas e Sul/Sudoeste de Minas, todas apresentando crescimento superiora 1,5\% a.a. De outra parte, há também mesorregiões que praticamente não cresceram, como oVale do Rio Doce, do Jequitinhonha e do Mucuri (esta última a única a apresentar uma taxa de crescimento negativo de $-0,35 \%)$.

Levando-se em consideração a queda das taxas de fecundidade em boa parte doestado, é pertinente supor que os diferenciais de crescimento positivo apresentados pelasdiversas regiões de Minas Gerais sejam reflexo das próprias dinâmicas migratórias regionais. De acordo com os dados referentes à migração de data fixa do Censo 2000, verifica-se uma aumento de 3,7\% nos movimentos migratórios entre Unidades da Federação (UFs). Noperíodo 1986/1991, foram contabilizados 5.012.251 registros de migração entre as UFs eentre 1995 e 2000 esse número evoluiu para 5.196.093, não obstante a diminuição daproporção de migrantes em relação à população total, de 3,4 para 3,1\% (IBGE, 2003).

No caso específico de Minas Gerais, as mudanças também se manifestaram. De um estado eminentemente expulsor de população, Minas também passou a receber grande volume de migrantes. Essa reversão no balanço migratório geral pode ser consequência tantodo aumento das entradas, quanto da queda das saídas. De 1986 a 1991, a diferença entre onúmero de imigrantes (371.886) e emigrantes (408.658) de Minas correspondia a -107.511pessoas. No período seguinte (1995/2000), esse diferencial era positivo e alcançava o total de 39.124 (447.782 imigrantes e 408.658 emigrantes). 


\section{Tabela1}

PopulaçãoresidenteetaxadecrescimentonasMesorregiõesdeMinasGerais-1991e2000

\begin{tabular}{|c|c|c|c|c|c|}
\hline \multirow{2}{*}{ Meso Regiões de Minas } & \multicolumn{2}{|c|}{1991} & \multicolumn{2}{|c|}{2000} & \multirow{2}{*}{$\begin{array}{l}\text { TCGAM } \\
*\end{array}$} \\
\hline & $\mathrm{N}^{\mathrm{o}}$ & $\%$ & $\mathrm{~N}^{\mathrm{o}}$ & $\%$ & \\
\hline Noroeste de Minas & 305.285 & 1,94 & 334.534 & 1,87 & 1,02 \\
\hline Norte de Minas & 1.359 .049 & 8,63 & 1.495 .284 & 8,35 & 1,07 \\
\hline Jequitinhonha & 658.238 & 4,18 & 679.850 & 3,80 & 0,36 \\
\hline Vale doMucuri & 395.319 & 2,51 & 382.977 & 2,14 & $-0,35$ \\
\hline Triângulo Mineiro/Alto Paranaíba & 1.595 .818 & 10,14 & 1.871 .237 & 10,45 & 1,78 \\
\hline Central Mineira & 348.315 & 2,21 & 381.601 & 2,13 & 1,02 \\
\hline Metropolitana de Belo Horizonte & 4.620 .624 & 29,35 & 5.588 .300 & 31,21 & 2,14 \\
\hline Vale doRioDoce & 1.461 .427 & 9,28 & 1.535 .177 & 8,57 & 0,55 \\
\hline Oeste de Minas & 726.059 & 4,61 & 839.112 & 4,69 & 1,62 \\
\hline Sul/SudoestedeMinas & 1.961 .401 & 12,46 & 2.251 .629 & 12,58 & 1,55 \\
\hline Campo das Vertentes & 464.907 & 2,95 & 511.956 & 2,86 & 1,08 \\
\hline Zona daMata & 1.847 .093 & 11,73 & 2.033 .478 & 11,36 & 1,07 \\
\hline Total & 15.743 .533 & 100,00 & 17.905 .134 & 100,00 & 1,44 \\
\hline
\end{tabular}

* Taxa de crescimento geométrico anual médio

Fonte: IBGE,Censo Demográfico 1991 e 2000 (Dados de Amostra)

Boa parte dessa mudança se deve às trocas populacionais com São Paulo, tradicional receptor de imigrantes procedentes de Minas. Conforme os dados da Tabela 2, dois fenômenos simultâneos e inter-relacionados podem ser sublinhados: i) o aumento absoluto e relativo dos imigrantes procedentes de São Paulo em Minas (de 145.823 de para 201.880 e de 39,2\% para 45,0\% e; ii) uma queda absoluta e relativa dos emigrantes de Minas em São Paulo (de 236.086 para 178.422 e de $16,9 \%$ para 14,5\%). Esses valores indicam a passagem de um diferencial negativo de 90.263 , para um positivo de 23.458 em relação a São Paulo.

Todavia, essa mudança nos diferenciais migratórios entre Minas e São Paulo traduz-se diferenciadamente se comparadas as trocas entre as mesorregiões e o estado vizinho, como mostra o conjunto de mapas da Figura 1. No período de 1986 a 1991, várias regiões mineiras apresentavam diferencial migratório negativo, exceto o Triângulo Mineiro/Alto Paranaíba e Campo das Vertentes. Já em São Paulo a grande maioria das regiões exibia ganhos de população (exceto a mesorregião de Presidente Prudente). As mesorregiões paulistas quetiveram saldos positivos mais expressivos foram Ribeirão Preto, Campinas e Vale do Paraíba.

No período seguinte, 1995/2000, essa situação se altera sensivelmente. Além do Triângulo Mineiro/Alto Paranaíba e Campo das Vertentes, outras mesorregiões mineiras, envolvendo toda a 
porção centro/oeste do estado, também passaram a apresentar diferenciais positivos ${ }^{2}$. Apenas as mesorregiões do norte e nordeste de Minas continuavam perdendo população para São Paulo (Norte, Jequitinhonha, Mucuri e Doce). Em São Paulo, as mesorregiões de Itapetininga, Presidente Prudente e Araçatuba passaram a ostentar saldos negativos.

\section{Tabela2}

Origem e destino dos migrantes de data fixa, residentes em Minas Gerais e em São Paulo, conforme procedência regional no Brasil$1986 / 91 \mathrm{e} 1995 / 2000$

\begin{tabular}{|c|c|c|c|c|c|c|c|c|}
\hline \multirow{4}{*}{ ORIGEM } & \multicolumn{8}{|c|}{ DESTINO } \\
\hline & \multicolumn{4}{|c|}{ MINAS GERAIS } & \multicolumn{4}{|c|}{ SÃO PAULO } \\
\hline & \multicolumn{2}{|c|}{$1986 / 91$} & \multicolumn{2}{|c|}{$1995 / 2000$} & \multicolumn{2}{|c|}{ 1986/91 } & \multicolumn{2}{|c|}{$1995 / 2000$} \\
\hline & N. & $\%$ & N. & $\%$ & N. ${ }^{\circ}$ & $\%$ & N. & $\%$ \\
\hline MG & $\mathrm{xxx}$ & $\mathrm{xxx}$ & $\mathrm{xxx}$ & $\mathrm{xxx}$ & 236.086 & 16,95 & 178.422 & 14,58 \\
\hline $\mathrm{SP}$ & 145.823 & 39,21 & 201.880 & 45,08 & $\mathrm{xxx}$ & $\mathrm{xxx}$ & $\mathrm{xxx}$ & $\mathrm{xxx}$ \\
\hline ES & 27.725 & 7,46 & 29.529 & 6,59 & 8.864 & 0,64 & 10.826 & 0,88 \\
\hline $\mathrm{RJ}$ & 58.084 & 15,62 & 57.049 & 12,74 & 63.291 & 4,54 & 46.959 & 3,84 \\
\hline $\mathrm{N}$ & 18.622 & 5,01 & 16.866 & 3,77 & 34.796 & 2,50 & 30.713 & 2,51 \\
\hline $\mathrm{NE}$ & 48.838 & 13,13 & 65.085 & 14,53 & 720.561 & 51,74 & 705.648 & 57,66 \\
\hline $\mathrm{S}$ & 20.369 & 5,48 & 20.671 & 4,62 & 245.270 & 17,61 & 165.587 & 13,53 \\
\hline $\mathrm{CO}$ & 52.425 & 14,10 & 56.702 & 12,66 & 83.923 & 6,03 & 85.657 & 7,00 \\
\hline Total & 371.886 & 100,00 & 447.782 & 100,00 & 1.392 .791 & 100,001 & 23.811 & 100,00 \\
\hline
\end{tabular}

Adicionalmente, é oportuno frisar que, no período 1995/2000, todas as mesorregiões de Minas apresentaram um aumento absoluto no número de imigrantes de data fixa procedentes de São Paulo (ver Gráfico 1). Em alguns casos, como no Sul/Sudoeste de Minas, a presença desses imigrantes aumentou de 36,6\% para 39,3\% do total. As regiões do Triângulo Mineiro/Alto Paranaíba e Metropolitana de Belo Horizonte, apesar da pequena redução em termos absolutos, também mantiveram-se como importantes áreas de atração. Em contrapartida, as regiões do Noroeste de Minas, Central Mineira e Vale do Mucuri têm recebido parcelas menos expressivas de imigrantes oriundos de São Paulo, mesmo tendo diminuído o número de emigrantes.

\footnotetext{
${ }^{2}$ Ainda nesse período, destacam-se os ganhos apresentados pelo Sul/Sudoeste de Minas (36.000 pessoas) e as perdas da mesorregião Metropolitana de São Paulo (diferencial negativo de 45.916).
} 
Diferencial migratório nas trocas populacionais entre

Minas Gerais e São Paulo - 1986/1991 e 1995/2000

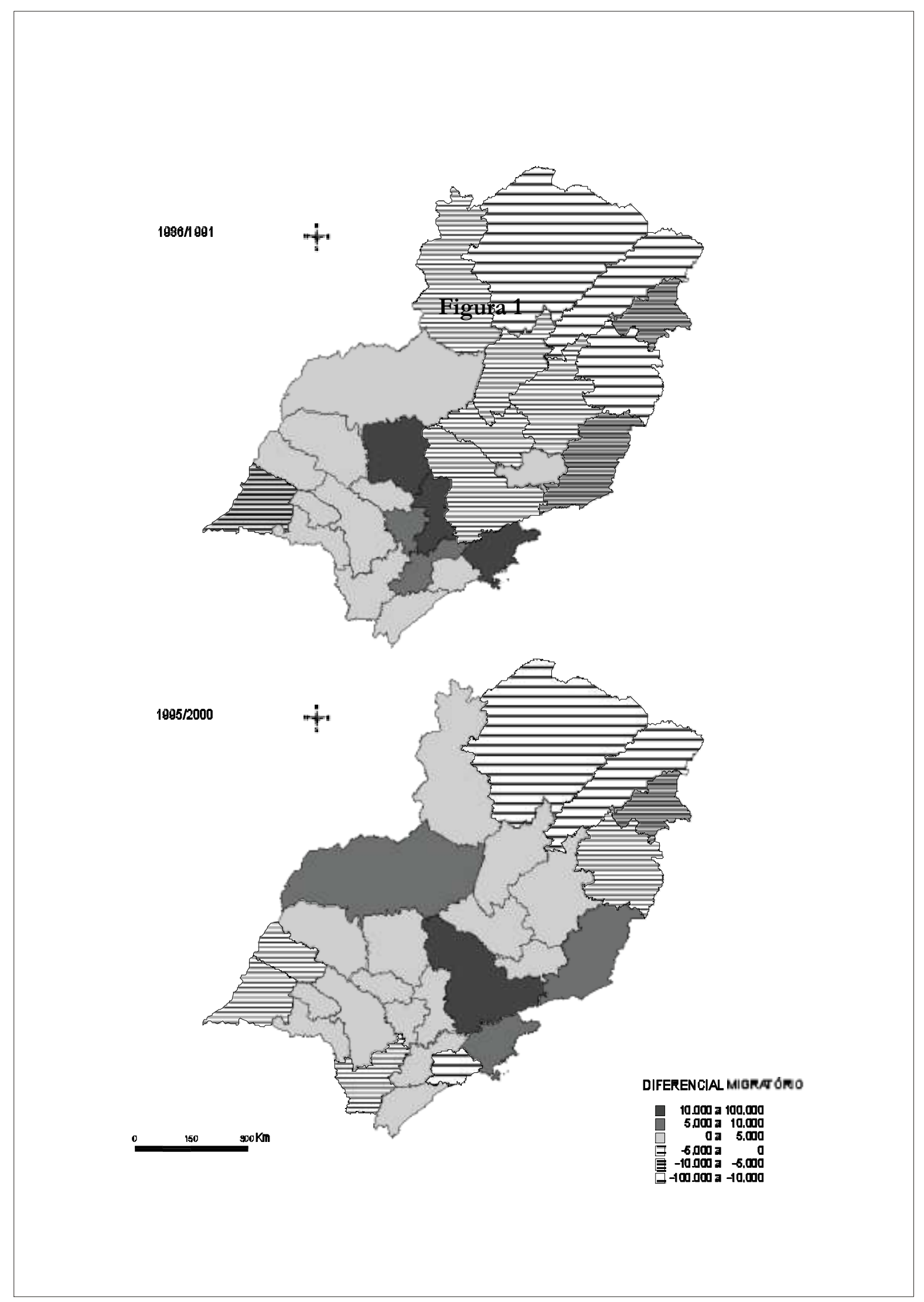




\section{Gráfico 1}

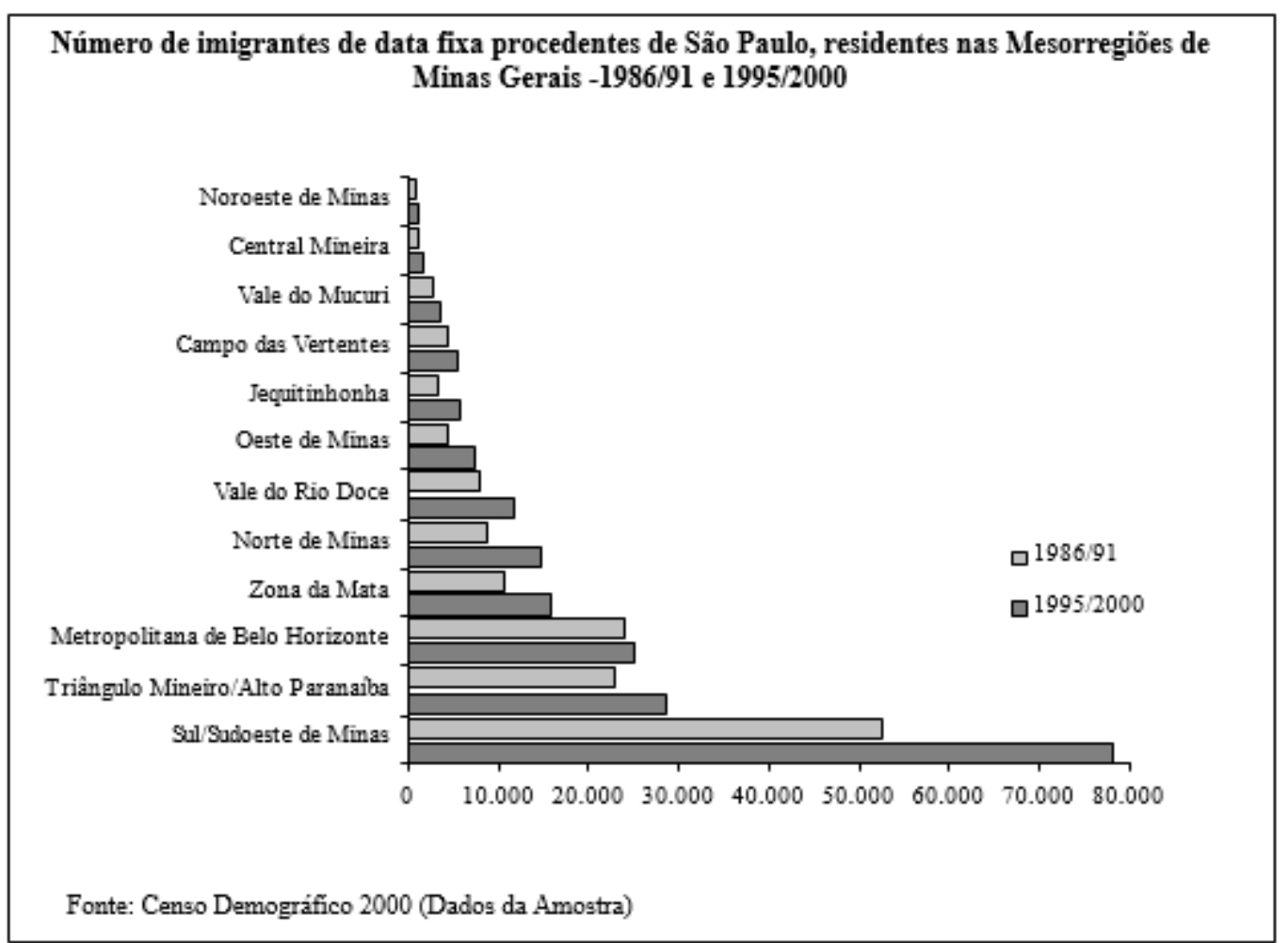

Fonte: IBGE, Censos Demográficos de 1991 e 2000.

Há, no entanto, especificidades que são reveladas apenas quando comparadas as trocas diretas entre as mesorregiões dos dois estados. Ao analisarmos as origens regionais dos imigrantes procedentes de São Paulo, verifica-se a forte contribuição da mesorregião Metropolitana de São Paulo, como ilustrado na Figura 2. Esse contingente englobava um total de 118.369 pessoas, o que corresponde acerca de 58,6\% do total dos imigrantes residente sem Minas Gerais. As mesorregiões mineiras que mais receberam migrantes procedentes dessa região foram nessa ordem: Sul/Sudoeste de Minas, Metropolitana de Belo Horizonte, Zonada Mata, Triângulo Mineiro/Alto Paranaíba e Norte de minas (todos com mais de 10.000imigrantes). Outra importante mesorregião emissora de população para Minas foi Campinas, principalmente em relação àqueles grupos que se encaminharam para o Sul/Sudoeste de Minas e o Triângulo Mineiro/Alto Paranaíba. Com menor peso, comparecem as regiões de Ribeirão Preto e Vale do Paraíba do Sul, que também têm perdido população para Minas. 
Figura 2

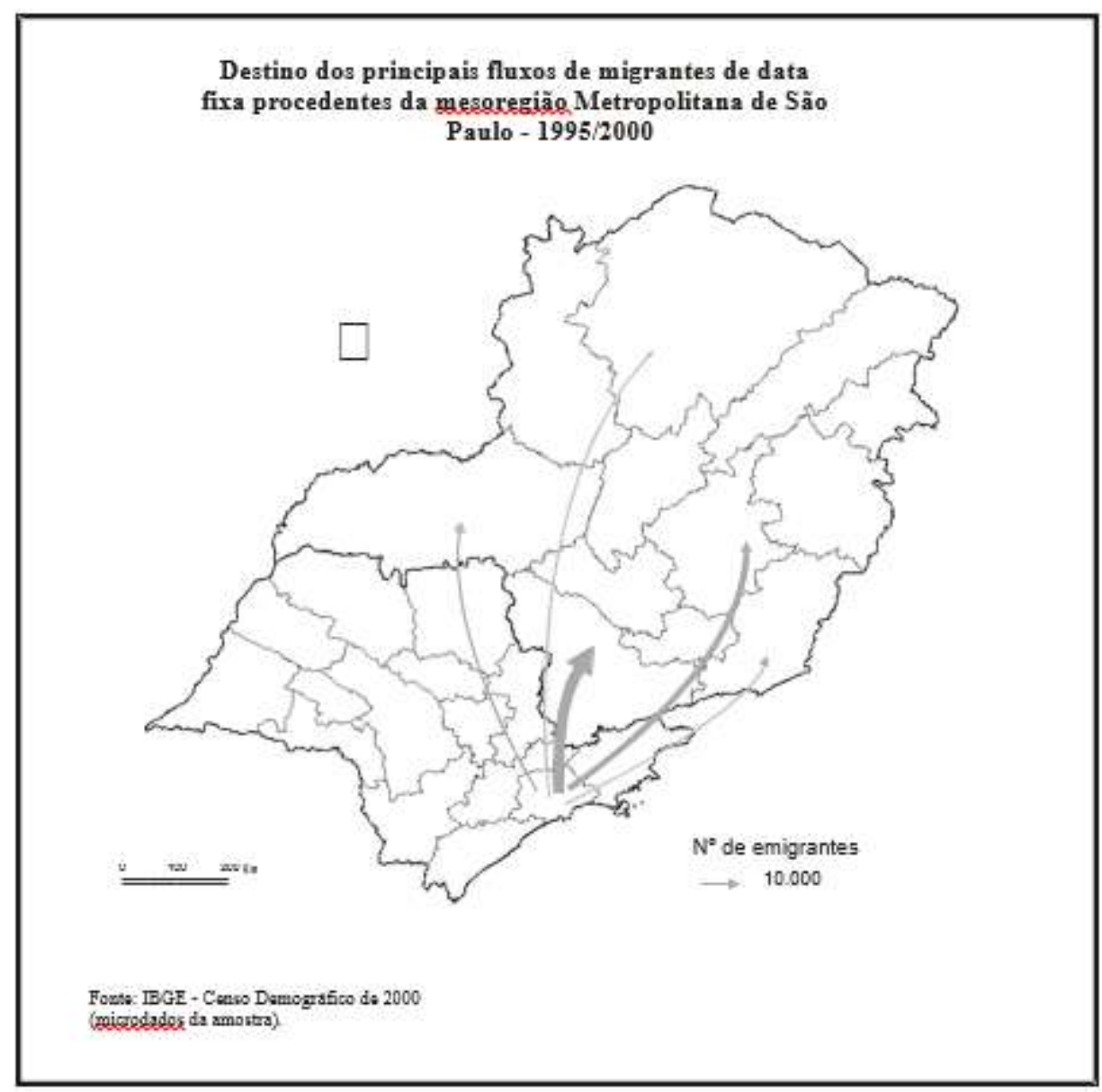

As alterações nos fluxos migratórios entre estes dois estados suscitam uma série que questões que certamente merecem ser analisada com mais detalhe. Seriam esses fluxos um resultado do movimento de retornados a Minas? Ou, diferentemente, representam contingentes de migrantes de passagem, que nascidos nas demais UFs do país tentaram a sorte em São Paulo e, em algum momento do último quinquênio, dirigiram-se ao estado vizinho? Há representatividade numérica dos imigrantes nascidos em São Paulo? Quais características econômicas e sociais podem ser típicas de cada um dos grupos de migrantes?Há semelhança no perfil desses grupos? Seriam os paulistas os migrantes com maior e melhor inserção ocupacional em Minas? Investigar tais questões pode ajudar a compreender melhor essa nova dinâmica migratória regional, podendo, inclusive, sugerir dimensões sócio demográficas intrínsecas aos movimentos populacionais. 


\section{3 - RETORNADOS A MINAS, PAULISTAS E NASCIDOS NAS DEMAIS UFS SEGUNDO PERFIL SÓCIOECONÔMICO}

Recortando o contingente de migrantes de data fixa do período 1995-2000, com idade igual ou superior a 15 anos, residentes em Minas Gerais, nota-se que há uma predominância dos imigrantes retornados à Unidade da Federação de nascimento. Dos 154.829 imigrantes procedentes de São Paulo, 47,6\% nasceram em Minas. Entretanto, não obstante a representatividade desse grupo, destacam-se também os 38,6\% relativos a imigração de paulistas. Em algumas das mesorregiões mineiras, como no Triângulo Mineiro/Alto Paranaíba e do Sul/Sudoeste Mineiro, além Belo Horizonte, Zona da Mata e Norte de Minas a proporção de imigrantes nascidos em São Paulo representava 50,6 e 47,7\%, respectivamente (Tabela 3$)^{3}$.

\section{Tabela3}

Número de imigrantes de data fixa procedentes de São Paulo,

Com idade superior a 15 anos, residentes nas mesorregiões de Minas Gerais, 2000

\begin{tabular}{|c|c|c|c|c|c|c|}
\hline \multirow{3}{*}{ Mesorregiões de Minas } & \multicolumn{6}{|c|}{ Imigrantes deSão Paulo } \\
\hline & \multicolumn{2}{|c|}{ Retornados } & \multicolumn{2}{|c|}{ Paulistas } & \multicolumn{2}{|c|}{$\begin{array}{r}\text { Nascidos } \\
\text { das demais Ufs }\end{array}$} \\
\hline & $\mathrm{N}^{\mathrm{o}}$ & $\%$ & $\mathrm{~N}^{\mathrm{o}}$ & $\%$ & $\mathrm{~N}^{\mathrm{o}}$ & $\%$ \\
\hline Noroeste de Minas & 319 & 39,05 & 327 & 40,04 & 171 & 20,91 \\
\hline Norte de Minas & 7.336 & 68,45 & 2.113 & 19,71 & 1.268 & 11,84 \\
\hline Jequitinhonha & 3.203 & 76,73 & 545 & 13,06 & 426 & 10,21 \\
\hline Vale doMucuri & 1.758 & 69,74 & 446 & 17,68 & 317 & 12,58 \\
\hline Triângulo Mineiro/AltoParanaíba & 6.797 & 30,31 & 11.348 & 50,60 & 4.283 & 19,10 \\
\hline Central Mineira & 751 & 60,81 & 335 & 27,16 & 149 & 12,03 \\
\hline Metropolitana de Belo Horizonte & 10.325 & 49,63 & 6.974 & 33,52 & 3.507 & 16,86 \\
\hline Vale doRioDoce & 6.327 & 72,70 & 1.639 & 18,83 & 737 & 8,47 \\
\hline Oeste de Minas & 3.118 & 56,04 & 1.724 & 30,97 & 723 & 12,99 \\
\hline Sul/Sudoestede Minas & 23.905 & 39,04 & 29.184 & 47,66 & 8.149 & 13,31 \\
\hline Campo das Vertentes & 2.260 & 53,64 & 1.405 & 33,35 & 548 & 13,01 \\
\hline Zona daMata & 7.244 & 58,37 & 3.716 & 29,94 & 1.450 & 11,69 \\
\hline Total & 73.344 & 47,37 & 59.756 & 38,59 & 21.729 & 14,03 \\
\hline
\end{tabular}

Fonte: Censo Demográfico 2000 (Dados da Amostra)

\footnotetext{
${ }^{3}$ Em contrapartida, nas regiões do Vale do Jequitinhonha, do Mucurí e Norte de Minas a contribuição de imigrantes paulistas é pouco expressiva, não sendo superior aos $20 \%$. Nessas mesorregiões há uma clara predominância da migração de retorno, que no caso do Vale do Jequitinhonha chega a representar $76,73 \%$ do total de imigrantes procedentes de São Paulo.
}

Cadernos do Leste 
Do contingente de paulistas, é expressivo o número de imigrantes procedentes da região metropolitana de São Paulo (ver Figura3), que correspondem à 54,8\% do total de imigrantes. Em relação às demais origens regionais dos paulistas, que também são bastante significativas, nota-se maior relevância dos fluxos de Ribeirão Preto, Campinas, Vale do Paraíba e Macro Metropolitana para o Sul/Sudoeste de Minas e de Ribeirão Preto para o Triângulo Mineiro/Alto Paranaíba.

Nesse sentido, além da conhecida migração de retorno, sobretudo no tocante aos fluxos com destino às regiões que historicamente têm perdido população para São Paulo, a chegada de expressivos contingentes de paulistas à Minas,em sua maioria compostos por jovens em idade ativa,como observado nos conjunto demográficos em sequência, parece sugerir novos mecanismos no processo de redistribuição espacial da população ema algumas das regiões mineiras,o que necessariamente tem marcado as territorialidades no estado. A análise sobre as principais características de cada um dos subgrupos de imigrantes pode trazer indícios de importantes elementos que compõem a dinâmica migratória regional.

\section{O perfil dos retornados, dos paulistas e dos nascidos nas demais UFs}

De um modo geral, os dados permitem concluir que os naturais de São Paulo são mais jovens que os demais grupos de migrantes (ver conjunto de Gráficos 1). Enquanto a mediana de idade dos imigrantes paulistas procedentes de São Paulo é de 27 anos, o valor para o grupo de retornados e para os nascidos nas demais UFs corresponde a 36 anos. Em determinadas mesorregiões, como o Vale do Mucuri, Zona da Mata e Central Mineira, a mediana dos imigrantes paulistas é inferior a 23 anos (muitos deles certamente filhos de migrantes mineiros). Contudo, entre os imigrantes paulistas nas messorregiões do Triângulo Mineiro/Alto Paranaíba e do Sul/Sudoeste Mineiro a idade mediana atinge os 30 anos. Eleva-se mais ainda se o grupo de referência for o de retornados a Minas, superando os 36 anos. Essa característica que marca as idades dos imigrantes paulistas nessas mesorregiões pode estar associada ao surgimento de oportunidades econômicas que requeiram pessoal mais qualificado e/ou mais experiente profissionalmente. É bem verdade que as ocupações tradicionais de menor nível de qualificação ainda são majoritárias, sobretudo aquelas relacionadas ao comércio (vendedores dos setores formal e informal), prestação de serviços (serviços domésticos, ajudantes de obras, ajudantes em geral) e ao trabalho braçal em atividades agropecuárias. Entretanto, ampliam-se também as ocupações associadas à gerência e produção em estabelecimentos agrícolas, supervisão técnica e assemelhados em indústrias e agroindústrias da RMBH, Zona da Mata, Sul/Sudoeste de Minas e Triângulo Mineiro/Alto Paranaíba. 
Figura3

Origem e destino dos principais fluxos de imigrantes de data fixa, com idade superior a 15 anos, procedentes das mesoregiões de São Paulo-1995/2000(Fluxos superiores a 1.500pessoas)
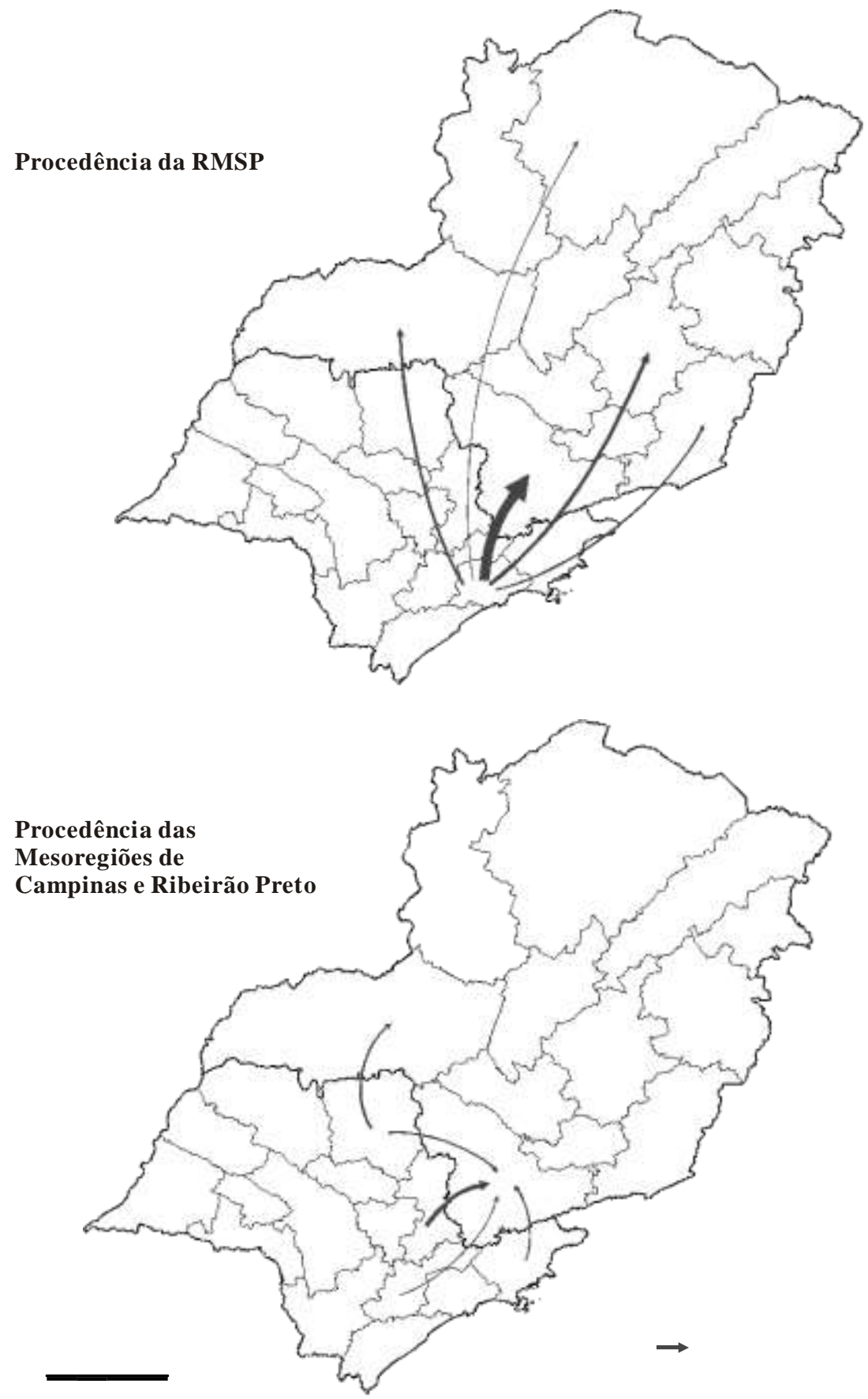


\section{Conjunto de Gráficos1}

Estrutura etária dos imigrantes de data fixa, procedentes de São Paulo, residentes nas Mesoregiões Metropolitana de Belo Horizonte, Sul/Sudoeste de Minas,Triângulo Mineiro/Alto Paranaíba e Norte de Minas,

$1995 / 2000$
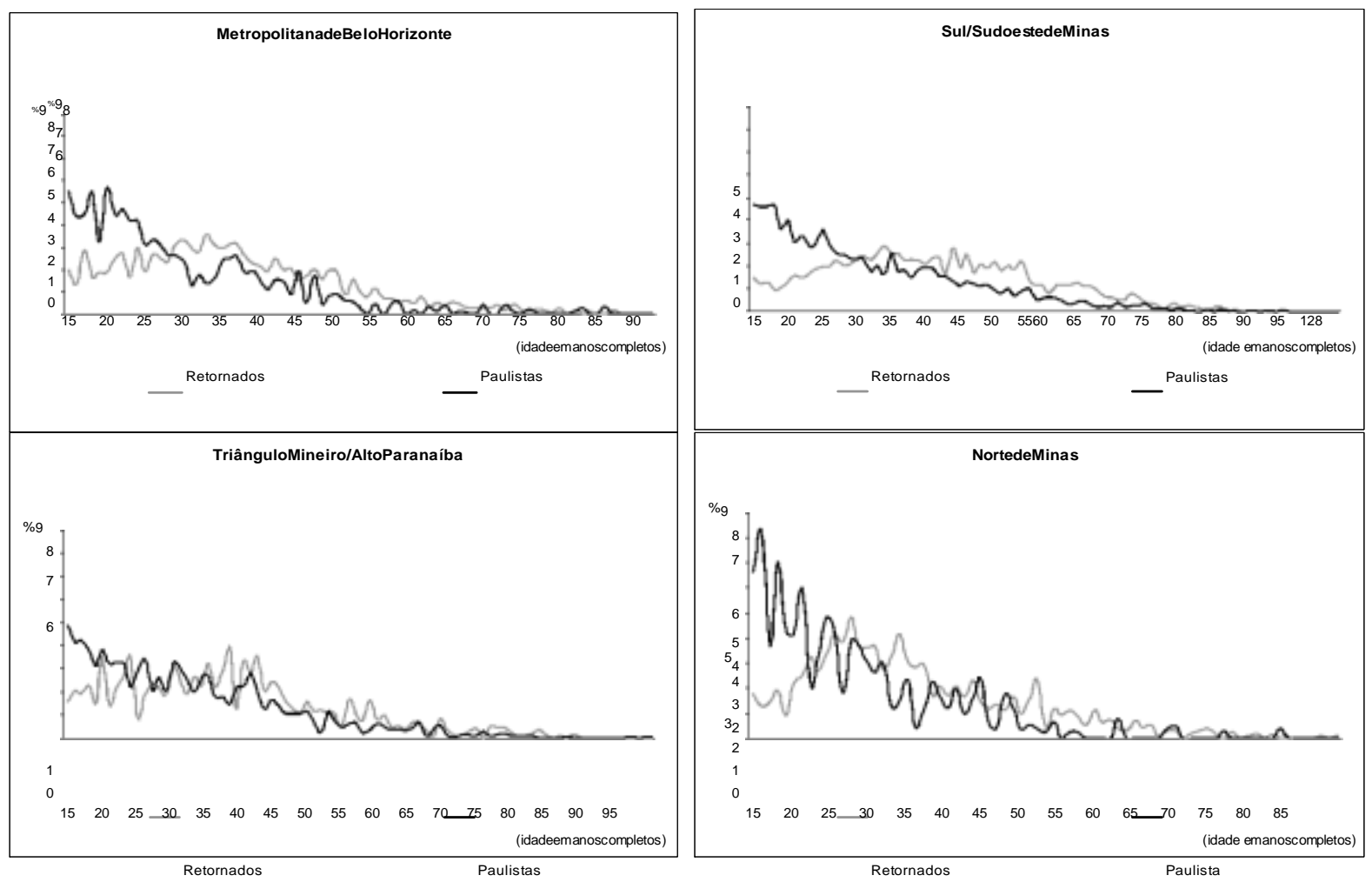

Fonte: Censo Demográfico 2000 (Dados da Amostra) 
Utilizando-se das informações referentes aos rendimentos individuais, constata-se que a maioria dos imigrantes paulistas residentes em Minas apresenta algum tipo de rendimento (59,64\%),embora essa proporção seja inferior àquela verificada para os imigrantes de retorno a Minas $(68,16 \%)$ e nascidos nas demais UFs $(66,96 \%)^{4}$. Em relação às mesorregiões, percebe-seque no Sul/Sudoeste de Minas e no Triângulo Mineiro/Alto Paranaíba os imigrantes paulistas com rendimento representam percentuais próximos àqueles verificados para os retornados e nascidos nas demais UFs. No entanto, ainda que o percentual de imigrantes paulistas com algum tipo de renda seja menor que o percentual dos demais subgrupos de imigrantes, a mediana de renda dos imigrantes paulistas $(2,32 \mathrm{~s} . \mathrm{m}$.) é superior à dos imigrantes retornados $(1,99 \mathrm{~s} . \mathrm{m}$.) e dos imigrantes nascidos nas demais UFs (2,04s.m.) (ver Tabela4). Esse diferencial pode estar relacionado, em boa medida, ao próprio tipo de ocupação e nível de escolaridade desses imigrantes. Além disso, a proximidade maior ou menor dos mercados de trabalho de São Paulo, tanto na capital e entorno, quanto em áreas mais dinâmicas do interior, parecem contribuir para a diferenciação dos rendimentos. De fato, essa suposição se confirma com as sensíveis diferenças observadas quando comparadas as diversas mesorregiões mineiras. Nas mais dinâmicas economicamente, como o Triângulo Mineiro/Alto Paranaíba, Sul/Sudoeste de Minas, Metropolitana de Belo Horizonte e Campo das Vertentes, os níveis de renda dos subgrupos de imigrantes apresentam diferenças proporcionalmente menores do que aquelas apresentadas nas demais mesorregiões do estado, notadamente nas regiões economicamente mais deprimidas.

\footnotetext{
${ }^{4}$ Apesar do maior número de jovens, tanto para o grupo de paulistas, quanto em relação aos retornados, aproporção de imigrantes aposentados ou pensionistas nessas mesorregiões gira em torno de $10 \%$, valor inferior apenas àquele verificado para a região do Campo das Vertentes $(11,7 \%)$.
} 
Tabela4

Mediana de renda dos imigrantes de data fixa procedentes de São Paulo, residentes em Minas Gerais, com idade superior a 15 anos e que auferiam renda, 1995/2000

\begin{tabular}{|c|c|c|c|}
\hline \multirow[b]{2}{*}{ Mesorregiões de Minas } & \multicolumn{3}{|c|}{ Imigrantes de São Paulo } \\
\hline & Retorno & Paulistas & $\begin{array}{r}\text { Naturais } \\
\text { demais UFs }\end{array}$ \\
\hline Noroeste de Minas & 2,65 & 3,31 & 3,31 \\
\hline Norte de Minas & 1,39 & 1,66 & 1,66 \\
\hline Jequitinhonha & 1,32 & 1,03 & 1,85 \\
\hline Vale do Mucuri & 1,00 & 1,14 & 2,52 \\
\hline Triângulo Mineiro/Alto Paranaíba & 2,32 & 2,65 & 1,99 \\
\hline Central Mineira & 2,00 & 1,59 & 1,39 \\
\hline Metropolitana de Belo Horizonte & 2,32 & 3,31 & 2,65 \\
\hline Vale doRioDoce & 1,60 & 1,42 & 1,99 \\
\hline Oeste de Minas & 1,99 & 1,85 & 2,04 \\
\hline Sul/SudoestedeMinas & 2,19 & 2,32 & 2,09 \\
\hline Campo das Vertentes & 2,12 & 2,65 & 1,42 \\
\hline Zona daMata & 2,00 & 1,85 & 2,52 \\
\hline Total & 1,99 & 2,32 & 2,04 \\
\hline
\end{tabular}

Fonte: Censo Demográfico2000 (Dados da Amostra)

Observando os dados expostos na Tabela 5, é possível verificar que, em um quadro mais geral, a média de anos de estudos dos imigrantes dos naturais do estado de São Paulo (8,1anos) também supera as médias calculadas para os demais grupos de imigrantes (6,2 para os retornados e 6,0 para aqueles nascidos nas demais UFs). Discriminando a análise por mesorregiões nota-seu ma grande variabilidade no conjunto de dados, não obstante uma certa superioridade nos níveis de escolaridade dos paulistas. As regiões mineiras que têm recebido migrantes paulistas com medianas de escolaridade mais elevadas são Metropolitana de Belo Horizonte e Noroeste de Minas. Também se destacam as meso da Zona da Mata, Triângulo Mineiro/Alto Paranaíba e Campo das Vertentes. Em relação aos migrantes de retorno e os naturais das demais UFs, mas melhores indicadores de escolaridade também dizem respeito às regiões do Triângulo Mineiro/Alto Paranaíba e Metropolitana de Belo Horizonte, com valores próximos a 7 anos.Chama atenção os baixos níveis de escolaridade dos retornados e os migrantes nascidos nas demais UFs residentes nas mesorregiões do Vale do Jequitinhonha,Mucuri, Rio Doce e Norte de Minas,com valores em torno de 4 e 5 anos. 
Tabela5

Média de anos de estudo dos imigrantes de data fixa procedentes de São Paulo, com idade superiora 15anos, residentes em Minas Gerais-1995/2000

\begin{tabular}{|c|c|c|c|}
\hline \multirow[b]{2}{*}{ Mesorregiões de Minas } & \multicolumn{3}{|c|}{ Imigrantes deSão Paulo } \\
\hline & Retorno & Paulistas & $\begin{array}{r}\text { Naturais } \\
\text { Demais } \\
\text { UFs }\end{array}$ \\
\hline Noroeste de Minas & 6,60 & 9,04 & 7,42 \\
\hline Nortede Minas & 5,44 & 7,64 & 5,09 \\
\hline Jequitinhonha & 4,52 & 5,85 & 4,24 \\
\hline Vale doMucuri & 4,32 & 7,74 & 5,82 \\
\hline Triângulo Mineiro/Alto Paranaíba & 7,32 & 8,28 & 5,78 \\
\hline Central Mineira & 5,87 & 7,45 & 4,40 \\
\hline Metropolitana de Belo Horizonte & 6,99 & 9,39 & 7,14 \\
\hline Vale do RioDoce & 5,15 & 7,85 & 5,07 \\
\hline Oeste de Minas & 6,55 & 7,52 & 6,89 \\
\hline Sul/Sudoestede Minas & 6,43 & 7,76 & 5,89 \\
\hline Campo das Vertentes & 6,61 & 8,46 & 7,17 \\
\hline Zona da Mata & 6,21 & 8,73 & 6,78 \\
\hline Total & 6,23 & 8,10 & 6,09 \\
\hline
\end{tabular}

Em síntese, percebe-se que os indicadores utilizados, como renda, escolaridade e ocupação, permitem identificar distinções tanto no âmbito dos grupos de imigrantes, quanto nas condições das diversas mesorregiões mineiras. Embora os paulistas apresentem níveis mais elevados de rendimento e escolaridade, os imigrantes retornados às regiões do Triângulo Mineiro/Alto Paranaíba, Metropolitana de Belo Horizonte e Sul/Sudoeste de Minas parecem ter conseguido boa inserção no mercado de trabalho regional. Todavia, ainda persiste, pelo menos nas regiões mineiras menos desenvolvidas, um grande volume de imigrantes de retorno que, provavelmente, não obtiveram sucesso no estado de São Paulo, seja pelas condições econômicas lá encontradas,pelas mudanças a favor da mecanização eliminando mão-de-obra, ou pelos baixos níveis de escolaridade e qualificação desses migrantes. 


\section{CONSIDERAÇÕESFINAIS}

Ainda que os fluxos migratórios interestaduais respondam pela saída de significativos contingentes de mineiros para São Paulo e outras regiões do Brasil, há indícios de novas tendências na dinâmica migratória regional, conforme sinalizamos dados do Censo Demográfico de 2000. De um estado eminentemente expulsor de população, Minas passou a receber crescentes contingentes imigratórios, especialmente aqueles procedentes do estado vizinho. Nas trocas populacionais com São Paulo, identificadas pela migração de data fixa, as entradas têm superado as saídas de migrantes em Minas.Além dos já conhecidos movimentos de espraiamento ao redor dos grandes pólos,como São Paulo, Rio de Janeiro,e mesmo Belo Horizonte, novos centros urbanos têm se fortalecido regionalmente. Em Minas, cidades de porte intermediário do Triângulo e Sul de Minas,como Uberlândia,Uberaba,Poços de Caldas, Pouso Alegre, Itajubá,Três Corações e Passos, por exemplo,têm se constituído em alternativa de fixação para migrantes procedentes de São Paulo.

No entanto, além da migração de retorno, que tem mantido sua relevância no interior dos fluxos migratórios interestaduais, como já citado recorrentemente na literatura, também se destaca a migração de paulistas em direção a Minas, sobretudo para as regiões mais próximas a SãoPaulo. Boa parte desses migrantes tem como origem as principais regiões paulistas, como Campinas, Ribeirão Preto e, principalmente,a própria Mesorregião Metropolitana de São Paulo.

Essa forte presença de imigrantes paulistas em Minas, mesmo que concentrada em áreas geograficamente mais próximas pode estar trazendo evidências acerca de um novo dinamismo regional. Em geral, apesar das diferenças regionais, dos baixos níveis de renda e escolaridade, há sinais de que uma significativa parcela de imigrantes oriundos de São Paulo (retornados a Minas ou paulista)tem obtido destacada inserção no mercado de trabalho local, principalmente nos centros urbanos do Sul/Sudoeste e Triângulo Mineiro/Alto Paranaíba,além da própria Mesorregião Metropolitana de Belo Horizonte. 


\section{REFERÊNCIASBIBLIOGRÁFICAS}

BAENINGER,Rosana.Redistribuiçãoespacialdapopulação:característicasetendênciasdocaso brasileiro.Notas de população. Santiago do Chile, n. 65, p. 145/202, Jun. 1997.

IBGE, Migração e deslocamentos-Resultado da Amostra. Rio de Janeiro, 2003.

MATOS, Ralfo.Questões técnicas acerca dos processos de concentração e desconcentração da população no espaço. Revista Brasileira de População, v. 12, n. 1-2, p 35-38, 1995.

RIGOTT, José I.R.Técnicas de mensuração das migrações, a partir de dados censitários: aplicação aos casos de Minas Gerais e São Paulo. Tese (Doutorado). Universidade Federal de Minas Gerais CEDEPLAR. Belo Horizonte/MG, 1999. 